\title{
Seasonal Hydrological Drought Indicator for Tropical Drought Identification
}

\author{
Kit Fai Fung, Yuk Feng Huang, and Chai Hoon Koo
}

\begin{abstract}
Drought's frequency, duration and severity are essentials for impact control and mitigation of droughts. This paper adopts 3-month seasonal scale Streamflow Drought Index (SDI-3) to analyze these drought characteristics for the tropical climate at the Central, Southern and East Coast regions of Peninsular Malaysia in 1997-2016. The identified drought events were then evaluated using four major historical events from five different locations. The results showed that SDI-3 identified the occurrences of all reported drought events but with deviated onset and duration. However, the SDI-3 was concluded to be suitable for hydrological drought monitoring with reasons of increased temperature, groundwater and forest replenishment, and human factors. The spatial analysis on the drought characteristics also showed that most of the areas are more prone to short-term droughts, with relatively higher severity at north part of the Central Region, north-west part of the Southern Region and central part of the East Coast.
\end{abstract}

Index Terms-Drought characteristics, hydrological drought, spatial analysis, streamflow drought index, tropical climate.

\section{INTRODUCTION}

Drought is a natural hazard where a deficit of water has occurred over a period of time, causing a shortage in water supply. Drought has its own distinct definitions depending on the purpose or specific interest of a study. In order to reduce the damages of droughts towards economies, societies and also environment, drought's frequency, duration and severity are usually defined for impact control and mitigation.

Since Malaysia is located in the tropical climate zone, high humidity and frequent rains are expected throughout the year. Furthermore, the two monsoon seasons namely, the southwest monsoon (SWM) and the northeast monsoon (NEM) are contributing high amounts of rainfall onto Malaysia annually. However, due to various reasons such as high temperature brought by El Niño-Southern Oscillation (ENSO) events, the country is also vulnerable to droughts and dry spells. For example, the continuous period of low rainfall associated with ENSO phenomenon in year 1998 has led to severe droughts in various parts of Peninsular Malaysia such as Selangor, Kuala Lumpur Federal Territory, Penang, Kedah and Kelantan [1]. The variation of rainfall over time and space are also the main reasons for droughts to happen in Malaysia. For example, the East Coast has exceptional

Manuscript received September 12, 2019; revised December 14, 2019 This work was supported by the Universiti Tunku Abdul Rahman Research Fund (UTARRF).

Kit Fai Fung, Yuk Feng Huang, and Chai Hoon Koo are with the Civil Engineering Department, Lee Kong Chian Faculty of Engineering and Science, Universiti Tunku Abdul Rahman, Selangor, Malaysia (e-mail: kitfaifung@gmail.com, huangyf@utar.edu.my, kooch@utar.edu.my). diverse rainfall between months, where strong winds and rains strike are predominant in November to January, but the conditions turn to driest from July to September [2]. It was also reported from historical droughts that there is high spatial variation in the rainfall distribution. For example, west Seremban experienced a severe drought in 2014 where the main supplying river Sg Batang Penar run dried and had to draw water from east Seremban, which has sufficient water available in contrary. Given the vulnerability of the country to drought events, it is important to monitor and mitigate droughts in order to reduce the impact on various industries that will eventually cause economic losses. Hence, monitoring of hydrological droughts is important to indicate the sufficiency of subsurface or surface water for industrial activities in Central Region; irrigation of oil palm plantations in Southern Region; and irrigation of rice, rubber and oil palm plantations in East Coast.

In the past, many indices have been developed to define different category of droughts e.g. the Standardized Precipitation Index (SPI) [3], the Reconnaissance Drought Index (RDI) [4] and the Standardized Precipitation Evapotranspiration Index (SPEI) [5] for meteorological droughts; the Palmer Drought Severity Index (PDSI) [6], the Crop Moisture Index (CMI) [7] and Normalized Difference Vegetation Index (NDVI) [8] for agricultural droughts; and the Palmer Hydrological Drought index (PHDI) [6], the Surface Water Supply Index (SWSI) [9] and Streamflow Drought index (SDI) [10] for hydrological droughts. Other than defining droughts, these indices have also been used for drought predictions [11]-[16]. Hence, the drought index proposed in this study can also be used for prediction of future droughts' occurrence, duration and severity that are useful for planning and preparation purposes.

Among the hydrological drought indices available, the SDI that has the advantage of requiring the least data input and computational power was chosen as the drought index to define hydrological droughts. Hence, it was proposed to develop SDI for Peninsular Malaysia and investigate its ability in characterizing and identifying seasonal hydrological droughts so that it can be used for monitoring or prediction in the future. In order to obtain the finest sensitivity level of drought definition, the 3-month cumulative streamflow calculation period was selected as the timescale for SDI in this study. Furthermore, a 3-month timescale has proven its capability in reflecting seasonal changes in humid or semi-humid tropical regions [17], [18].

As aforementioned, although the country is located in humid tropical region, the triggering factors such as rise in temperature due to ENSO events, the great variation of rainfall amount over time and space are contributing to the 
development of reduced and uneven distribution of rainfall. Eventually, this phenomenon resulted in reduced streamflow due to insufficient replenishment after a period of water deficits. Given the more frequent occurrences of droughts in the recent twenty years, the aim here is to investigate the seasonal hydrological drought in Central Region, Southern Region and East Coast from 1997 to 2016 using streamflow as the indicator with the following objectives:

1) To define the seasonal water deficits in Central Region, Southern Region and East Coast of Peninsular Malaysia under tropical climate using Streamflow Drought Index, with the timescale of 3-month;

2) To identify and characterize droughts using the "run theory";

3) To evaluate the accuracy of the SDI-3 in drought identification, in terms of occurrence, duration and onset;

4) To carry out spatial analysis on drought characteristics within the three regions.

\section{Materials AND Methods}

\section{A. Study Area and Data Acquisition}

The study area covers three regions in Peninsular Malaysia i.e. Central Region, Southern Region and East Coast. The Central Region consists of two main states namely, Kuala Lumpur and Selangor, with area of $243 \mathrm{~km}^{2}$ and $7964 \mathrm{~km}^{2}$ respectively. The Southern Region consists of three states: Johor, Malacca, and Negeri Sembilan. These three states made up a total of $27,560 \mathrm{~km}^{2}$, about $20.94 \%$ of lands for Peninsular Malaysia. As for the East Coast, the largest region in Peninsular Malaysia, consisting Kelantan, Terengganu and Pahang states, covers a total area of $63,976 \mathrm{~km}^{2}$ [19].

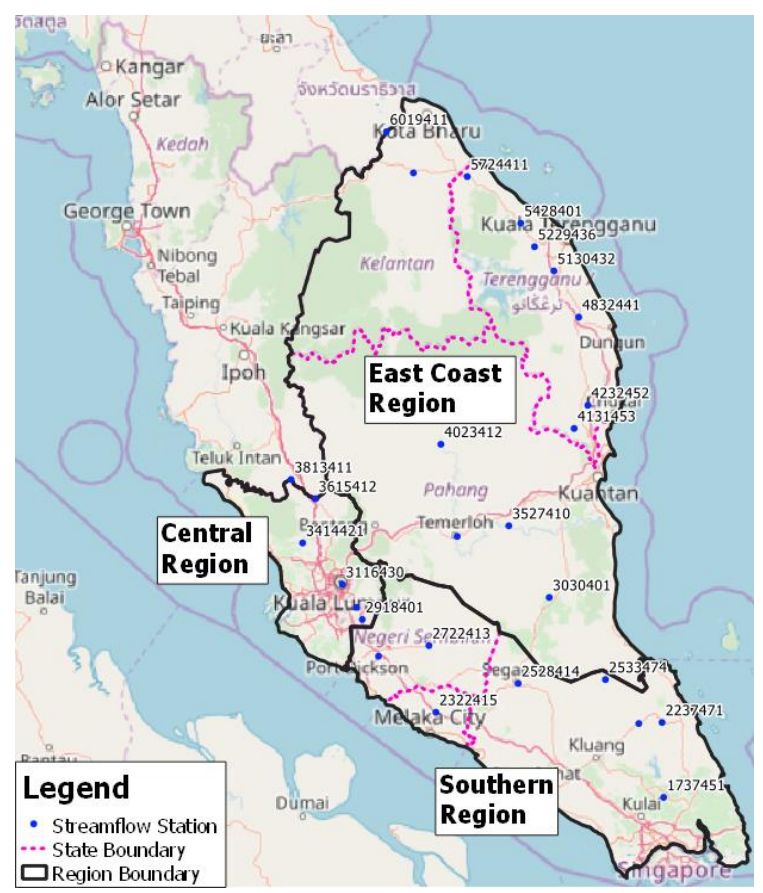

Fig. 1. Study area.

The monthly streamflow data was collected from Malaysia's Department of Irrigation and Drainage (DID), for the period from 1997 to 2016. Among the stations available, there are only twenty-seven well-functioning streamflow stations with recording of at least twenty years of continuous historical streamflow data for the study area, as shown in Fig. 1. Hence, these stations were selected to represent the streamflow drought conditions.

\section{B. Streamflow Drought Index (SDI)}

The SDI describes the moisture conditions based on the monthly streamflow volumes. It was utilized to identify hydrological drought in this study. Based on the cumulative streamflow volume $\left(V_{i, k}\right)$, SDI was calculated in a manner similar to normal standardization procedure, which was given as

$$
S D I_{i, k}=\frac{V_{i, k}-\bar{V}_{k}}{s_{k}}
$$

where $\bar{V}_{k}$ and $s_{k}$ are respectively the mean and the standard deviation of cumulative streamflow volumes of reference period $k$ (3-month). The classification of hydrological drought based on SDI value was given in Table I. Four major drought categories were classified by the different values of SDI.

\begin{tabular}{ll}
\multicolumn{2}{c}{ TABLE I: THE CATEGORIES OF SDI } \\
\hline \hline Criterion & Description \\
\hline SDI $\geq 0.0$ & Non-drought \\
$-1.0 \leq$ SDI $<0.0$ & Mild drought \\
$-1.5 \leq$ SDI $<-1.0$ & Moderate drought \\
$-2.0 \leq$ SDI $<-1.5$ & Severe drought \\
SDI $\leq-2.0$ & Extreme drought \\
\hline \hline
\end{tabular}

\section{Drought Dentification and Drought Characteristics}

This study applies the "run theory" proposed by Yevjevich [20] for drought characterization. It has been frequently used on time series of irregular hydrologic events to identify drought components and investigate their statistical properties [21], [22]. A "run" is defined as a portion of time series of the variable that is less than the chosen threshold [23], [24]. Following Nalbantis and Tsakiris [18], the drought event in this study is defined as the period where SDI values are less than the threshold value of zero. The time span of each event is defined as drought duration (DD) and the cumulative negative values below the truncation level is defined as the drought severity (DS).

In order to investigate the spatial variation of drought characteristics, three event indices were estimated based on drought events identified by the "run theory" in each station. First of all, drought frequency (DF) was estimated to represent the total number of droughts occurred during 1997-2016. With the occurrences identified, the average duration and severity were also identified as mean drought duration (MDD) and mean drought severity (MDS), respectively, to characterize droughts in the regions, as shown in the equations below:

$$
M D D=\frac{\sum_{i=1}^{N} D D_{i}}{N}
$$




$$
M D S=\frac{\sum_{j=1}^{N} D S_{j}}{N}, D S=\sum_{i=1}^{D D} S D I_{i}, D S<0
$$

Thereafter, the Inverse Distance Weighting (IDW) method was used to interpolate and analyze the spatial variations of drought characteristic across each region, as shown in the following equation:

$$
\hat{Z}=\frac{\sum_{i=1}^{n} \frac{Z_{i}}{d_{i}^{k}}}{\sum_{i=1}^{n} \frac{1}{d_{i}^{k}}}
$$

where $\hat{Z}$ is the estimated value at an unsampled point, $n$ is the number of control point used for estimation, $k$ is the power of which distance is raised, $\mathrm{d}$ is the distances from each control points to un-sampled point.

\section{RESULTS AND DISCUSSION}

\section{A. Evaluation of Index's Accuracy}

As aforementioned, the "run theory" was used to identify droughts detected by SDI-3 in this study. Events with continuous SDI-3 values lower than zero were identified as drought events and compared with reported historical drought to evaluate the performance of SDI-3 in defining droughts, as shown in Table II below.

\begin{tabular}{|c|c|c|c|c|c|c|c|c|c|c|c|}
\hline Region & Areas & $\begin{array}{l}\text { Nearest } \\
\text { Streamflow } \\
\text { Station }\end{array}$ & $\begin{array}{l}\text { Actual } \\
\text { Onset }\end{array}$ & $\begin{array}{l}\text { Actual } \\
\text { End }\end{array}$ & $\begin{array}{l}\text { Identified } \\
\text { Onset }\end{array}$ & $\begin{array}{l}\text { Identified } \\
\text { End }\end{array}$ & $\begin{array}{c}\text { Onset } \\
\text { Difference } \\
\text { (Months) }\end{array}$ & $\begin{array}{c}\text { Actual } \\
\text { Duration } \\
\text { (Months) }\end{array}$ & $\begin{array}{l}\text { Identified } \\
\text { Duration } \\
\text { (Months) }\end{array}$ & $\begin{array}{c}\text { Duration } \\
\text { Difference } \\
\text { (Months) }\end{array}$ & Source(s) \\
\hline \multirow[t]{2}{*}{ Central } & Bangi & 2816441 & Apr-98 & Sep-98 & $\begin{array}{l}\text { i) Mar-98 } \\
\text { ii) Sep-98 }\end{array}$ & $\begin{array}{l}\text { i) Apr-98 } \\
\text { ii) Sep-98 }\end{array}$ & -1 & 6 & 3 & -3 & 1) Conference Proceeding [1] \\
\hline & Hulu Langat & 2816441 & Apr-12 & Sep-12 & Jul-12 & Sep-12 & 3 & 6 & 3 & -3 & $\begin{array}{l}\text { 1) Newspaper: The Star } \\
\text { Author: Regina Lee } \\
\text { Title: Water crisis looms in } \\
\text { Selangor } \\
\text { Date: } 18 \text { Jun } 2012 \\
\text { 2) Newspaper: The Star } \\
\text { Author: Mazwin Nik Anis } \\
\text { Title: Dry spell to worsen } \\
\text { situation } \\
\text { Date: } 19 \text { Jul } 2012\end{array}$ \\
\hline \multirow[t]{2}{*}{ Southern } & $\begin{array}{l}\text { Gemencheh } \\
\text { Dam }\end{array}$ & 2722413 & Jan-14 & Apr-14 & Mar-14 & Apr-14 & 2 & 4 & 2 & -2 & $\begin{array}{l}\text { 1) Newspaper: The Star } \\
\text { Author: Sarban Singh } \\
\text { Title: Water levels at four } \\
\text { dams continue to drop } \\
\text { Date: } 21 \text { Feb } 2014\end{array}$ \\
\hline & $\begin{array}{l}\text { Durian } \\
\text { Tunggal } \\
\text { Dam }\end{array}$ & 2322415 & Apr-16 & Oct-16 & Mar-16 & Jul-16 & -1 & 7 & 5 & -2 & $\begin{array}{l}\text { 1) Newspaper: The Star } \\
\text { Author: Sarban Singh } \\
\text { Title: Water woes loom in } \\
\text { Malacca with three } \\
\text { dams critical } \\
\text { Date: } 25 \text { Oct } 2016\end{array}$ \\
\hline East Coast & $\begin{array}{l}\text { Kelantan } \\
\text { River } \\
\text { (Guillemard } \\
\text { Bridge) }\end{array}$ & 5721442 & Jun-97 & Apr-98 & Apr-97 & Apr-98 & -2 & 11 & 13 & 2 & Conference Proceeding [1] \\
\hline
\end{tabular}

TABLE II: COMPARISON BETWEEN ACTUAL AND IDENTIFIED DROUGHTS

The differences between reported and SDI-3 identified events, in terms of drought onset and duration were used to evaluate the drought identification accuracy of SDI-3. As tabulated in Table II, there were four major historical drought events that had occurred in the regions during the period 1997-2016, and these were in 1998, 2012, 2014 and 2016.

For 1997/98 drought, it was one of the most significant droughts in the history. According to [1], this event impacted 1.8 million residents in Bangi area. During the event, although downpours were experienced in the impacted area, there was no rain at the upper Langat River catchment, from where the water supply is sourced. The prolonged rainfall deficit since the middle of 1997 has also resulted in the minimum flow of $82.5 \mathrm{~m}^{3} / \mathrm{s}$ for Kelantan River at Guillemard Bridge [1]. At this minimum flow, the river level was lower than the required irrigation abstraction level and thus, rendering the Pasir Mas Pump House in-operational. Fig. 2 and Fig. 3 show the changes in SDI-3 values in 1997/98 drought at station 2816441 (for Bangi) and station 5721442 for Guillemard Bridge), respectively. It can be seen that both stations experienced mild drought with fluctuating severity of magnitude less than -1.00 during the event.

For both cases, the drought onset identified by the SDI-3 showed an early detection of 1-month and 2-month, respectively. For these early identifications of onset, it may be explained as due to the ENSO event that had started to develop in Apr 1997. The long period of increased temperature caused by the ENSO event resulted in higher atmospheric water demand. Hence, even if there are rainfalls available, the streamflow may also be reduced as a consequence of the high evaporation and evapotranspiration rates, especially when there is a large tropical forest area at 
the upstream. In view of these reasons, the SDI-3 identified the drought earlier than expected as it defines droughts based on the water deficit observed from streamflow amount. Contrary to the early detection in onset, the endings of both events were identified accurately with the SDI-3, showing that it is applicable for drought identification.

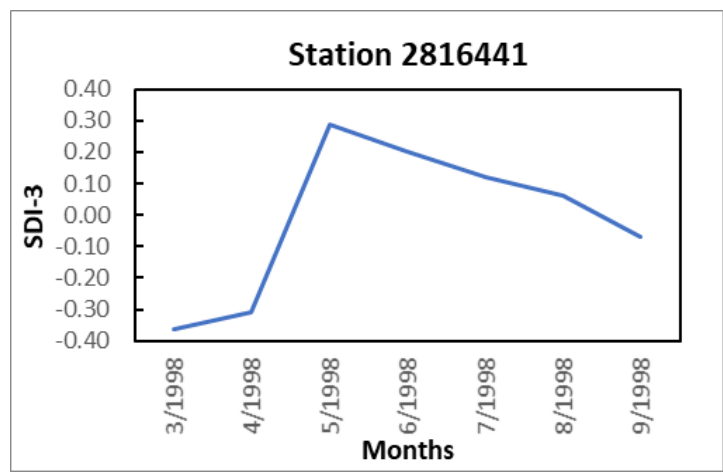

Fig. 2. SDI-3 values of station 2816441 during the drought in 1997/98.

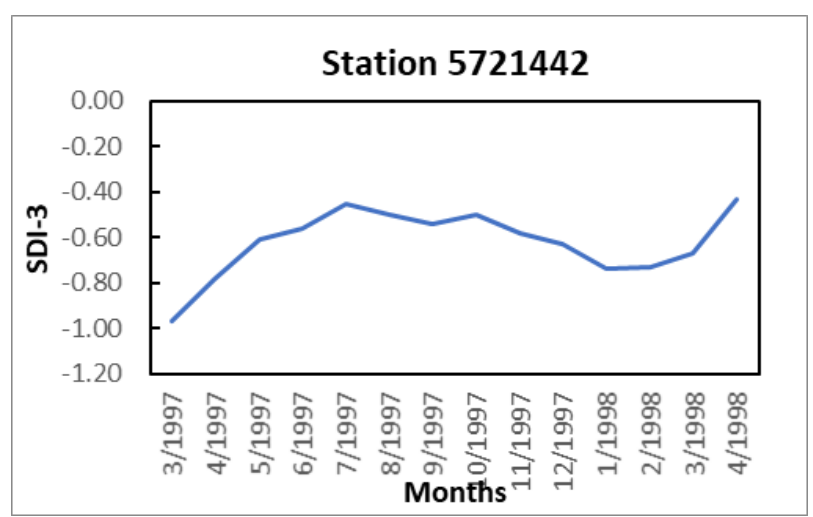

Fig. 3. SDI-3 values of station 5721442 during the drought in 1997/98.

For the reported drought at Hulu Langat in year 2012 (Table II), it caused drastically low levels in Selangor's "balancing reservoirs" for treated water and increased demand for water. The event was reported to have started in Apr and lasted until Sep. Compared to the SDI-3 identified period of Jul to Sep 2012, there is a difference of 3-month delay in onset and 3-month short in the duration. With the station 2816441 located at the upstream that is further from city and has larger forest areas, the delay in identified onset was deemed to be caused by the replenishment from water reserved in the forest that interrupted the changes in streamflow during the early drought. Apart from this, with the study area being in a humid tropical climate region, it is also deemed that there was replenishment from the groundwater during the early period of the drought event. As for the shorter duration, it may be explained by relating to the findings stating that the main causing factor of the event was due to the high water demand during the dry spell. With the mitigation taken i.e. water ration to lessen the impacts, streamflow was able to return to normal level immediately once the drought ended as the reducing streamflow was controlled. Hence, the SDI-3 plotted in Fig. 4 showed that the maximum severity of this event was only up to -0.80 (mild drought) in Aug 2012. This explains the shorter drought duration identified that caused by the delayed onset and exact ending of the drought identified by SDI-3.

As for the drought at the Gemencheh Dam in 2014 (Table
II), the drought identified by SDI-3 again showed a delay (2-month) on the drought onset and a short (2-month) in drought duration. This drought was again caused by the abnormally high water demand during dry spells. Similarly, the location of streamflow station of being in forest area delayed the identification of onset and the drought impact was lessening through water rationing. Hence, the SDI-3 again seems to be suitable for drought identification.

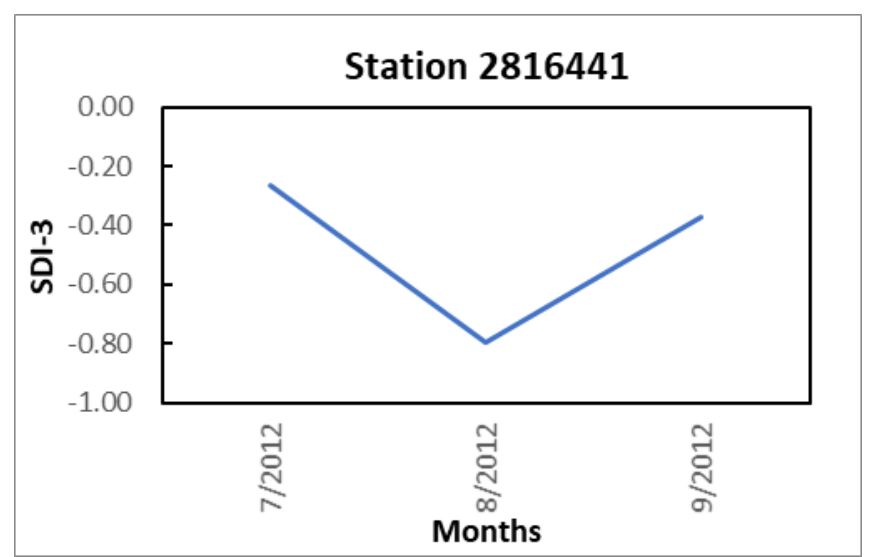

Fig. 4. SDI-3 values of station 2816441 during the drought in 2012.

Other than droughts caused by atmospheric water demand e.g. high evaporation or evapotranspiration due to high temperature, the previous two cases showed that SDI-3 seem to have an advantage of including human factors in identifying droughts. In other words, for droughts being a natural hazard that develop from different factors, SDI-3 seem to be a suitable index as the streamflow utilized considers the impacts from every drought developing factors and affects the water supply for domestic or irrigation use directly.

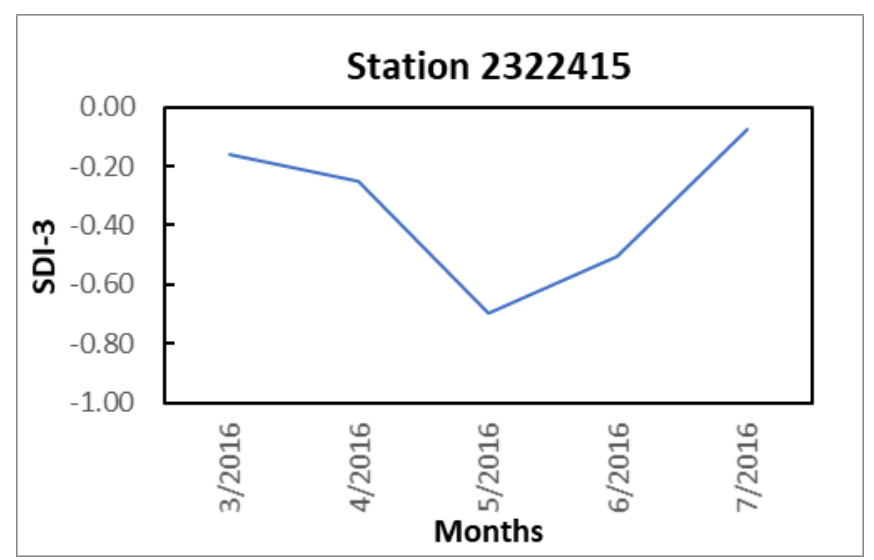

Fig. 5. SDI-3 values of station 2322415 during the drought in 2016.

Lastly, a drought at the Durian Tunggal Dam in year 2016 was also identified by the SDI-3. The event started in Apr 2016 and ended in Oct 2016 due to the impact from ENSO event (Table II). For this event, the nearest station 2322415 for the SDI-3 showed an early detection of 1-month and 2-month shorter compared to the reported duration. For the early detection, it may due to the long period of increased temperature during the ENSO event since year 2015. This resulted in higher atmospheric water demand and caused the start of reduction at station 2322415 in March but with a very low severity of -0.16 , as shown in Fig. 5. As for the shorter duration, it is deemed to be caused by the localized rainfall in 
the area. The state was reported to experience heavy downpours but there was no rain over the Durian Tunggal dam, suggesting that the drought may have ended for most of the state (including station 2322415) but continues at the dam.
All these show that the SDI-3 is applicable for drought identification but however, more stations are needed to solve the problem of spatial varying rainfall in the study area.

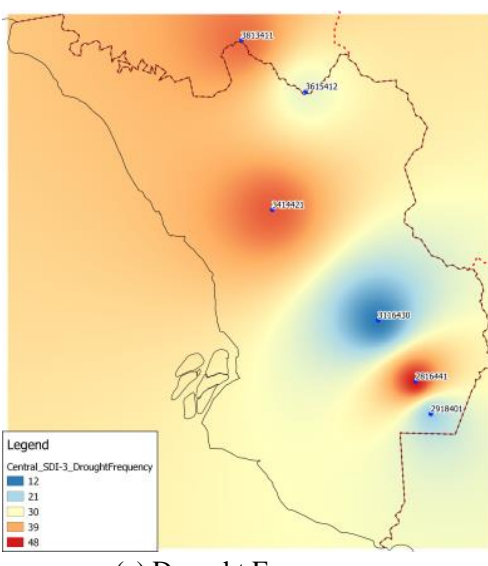

(a) Drought Frequency

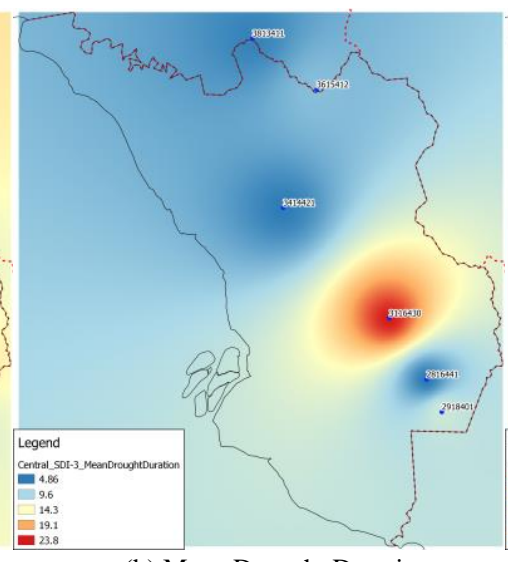

(b) Mean Drought Duration

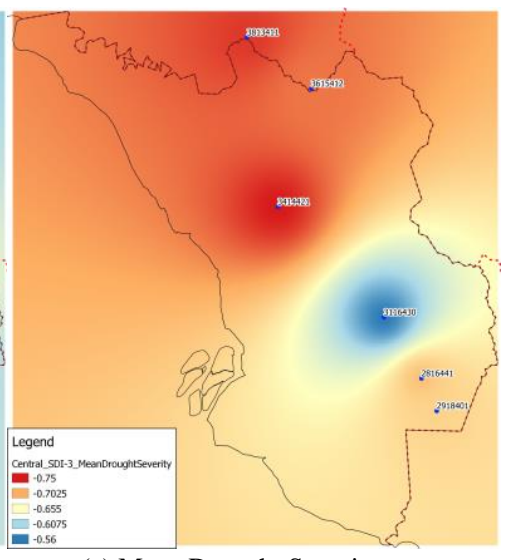

(c) Mean Drought Severity

Fig. 6. Heat maps for (a) drought frequency (DF), (b) mean drought duration (MDD) and (c) mean drought severity (MDS) of Central Region.

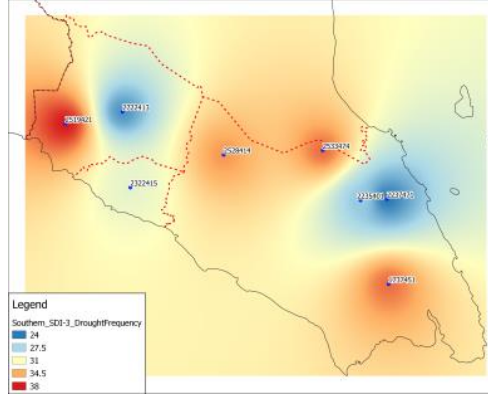

(a) Drought Frequency

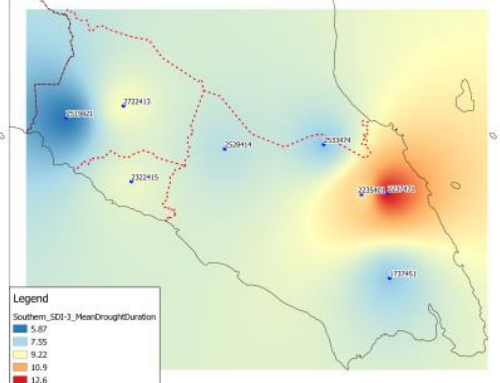

(b) Mean Drought Duration

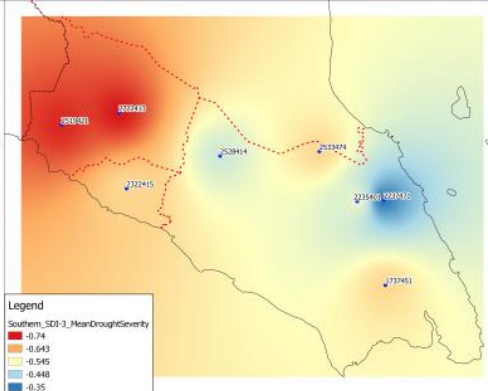

(c) Mean Drought Severity

Fig. 7. Heat maps for (a) drought frequency (DF), (b) mean drought duration (MDD) and (c) mean drought severity (MDS) of Southern Region.

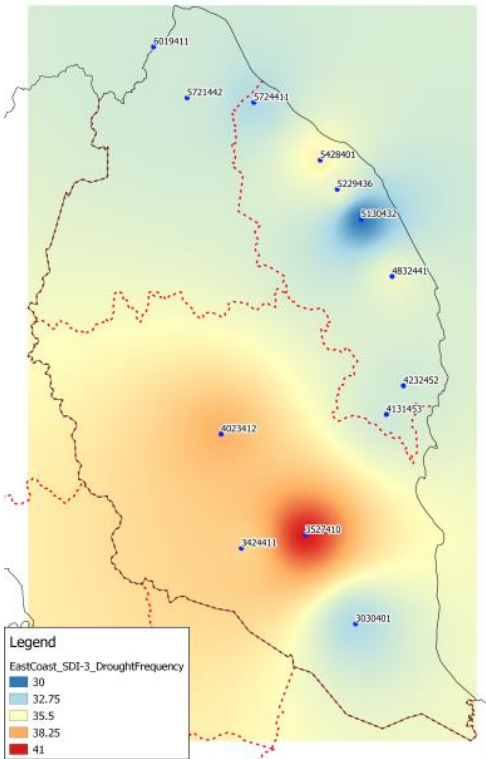

(a) Drought Frequency

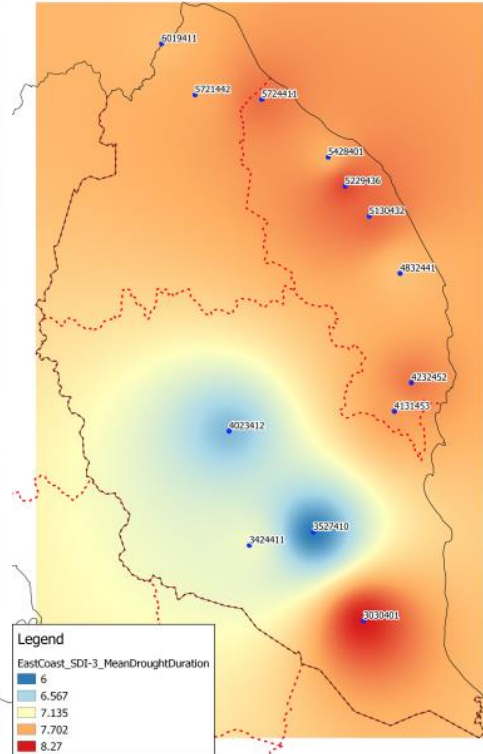

(b) Mean Drought Duration

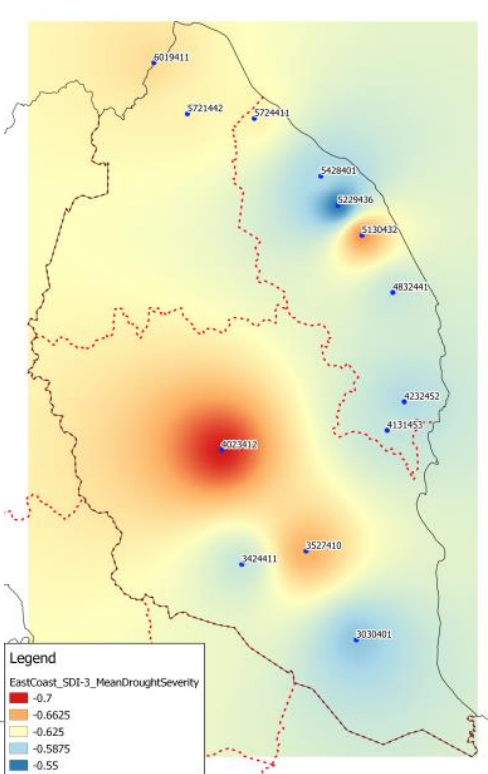

(c) Mean Drought Severity

Fig. 8. Heat maps for (a) drought frequency (DF), (b) mean drought duration (MDD) and (c) mean drought severity (MDS) of East Coast.

With the applicability of SDI-3 confirmed, the results from each station in the three regions were characterized into DF, MDD and MDS. Then, visual interpretations for each region were created by mapping the characteristics into a raster surface spatial map to analyze the variation over space (Fig. 6 to Fig. 8).

Based on Fig. 6(a), it can be observed that the drought events identified with the SDI-3 has the occurrence ranging in 12 to 48 times across the Central Region. Among the six stations investigated, relatively high DF values were identified from stations 2816441, 3414421 and 3813411, which are 48, 44 and 43 respectively. Other than that, the results of the MDS also showed that the averaged severity of these stations also possesses relatively high values of -0.69 , -0.75 and -0.74 respectively, compared to the severity of other stations showing values of not more than -0.65 (Fig. 
6(c)). In contrast, the MDD estimated from these stations are relatively low compared to other areas in the region (Fig. $6(\mathrm{~b})$ ), with duration of $4.85,5.00$ and 5.26 months respectively. These show that the Central Region has higher chance to encounter short-term drought that have relatively higher severity compared to long-term drought but lower severity.

As for the Southern Region, the spatial interpolation of drought characteristics showed that the water scarcity in terms of streamflow is more severe in the north-west part of the region. Based on Fig. 7, it can be seen that station 2519421 was identified to have 38 drought events in the past, with the MDD value of 5.87 months and MDS value of -0.73 . Compare to the DF, MDD and MDS of other stations in the region, the characteristics in station 2519421 differs significantly compared to all other stations. In view of the location of station 2519421 being at the end of the Titiwangsa Range, the significant difference of this station can be explained due to the "barrier effect" from the range that blocked the rainfall from the east and caused relatively dryer condition compared to other areas in the same region.

Over at the East Coast, the spatial pattern also varies in the region. For example, the stations at the center of the region namely, 3424411, 3527410 and 4023412 showed relatively higher occurrence of droughts compared to other areas. In addition, these identified droughts possess relatively higher severity but shorter duration, as shown in Fig. 8. Hence, it can be concluded that the East Coast has the drought characteristics of having higher frequency of droughts in the center part that have shorter duration but higher severity in nature.

By concluding the findings obtained from the spatial analysis, it can be summarized that although the droughts detected in each region have similar category of drought severity (mild drought), it is still undeniable that the drought characteristics vary even within the region. In view of this, it is recommended to increase the number of streamflow stations in order to provide a more evenly distributed observation of drought conditions in each region. Thereon, more accurate and detailed spatial representation of the drought characteristics across the region can be produced. Other than that, as the areas with more extreme drought characteristics were identified in this study, decision makers are able to visualize the priorities of the areas for the installation of additional streamflow stations.

\section{CONCLUSIONS}

This study investigates the hydrological droughts in the Central Region, Southern Region and East Coast of Peninsular Malaysia. Using the seasonal streamflow data as the indicator, the SDI was estimated for each of the twenty-seven stations with a 3-month timescale to define the seasonal droughts occurred in year 1997 to year 2016. Drought events identified by the SDI-3 through "run theory" were compared with four main historical events from five different areas to evaluate its drought identification accuracy. The evaluation results showed that all four events were correctly identified by the SDI-3 but the onset and duration differed from the reported events and this is explained as follows. Justifications such as an increase in evaporation and evapotranspiration rate due to prolonged high temperature caused by ENSO event, interruptions from groundwater and forest replenishments and human factors were available to justify the difference. Hence, the SDI-3 was concluded to be suitable for hydrological drought monitoring over Peninsular Malaysia. In view of the possibility that the differences may be caused by insufficient distribution of streamflow stations, it is recommended to increase the number of streamflow stations for better drought monitoring. DF, MDD and MDS were also estimated in this study to investigate the characteristics of droughts within each region. It was found that most of the areas in the three regions are more prone to short-term droughts with mean severity up to mild category. Although the drought severities categorized as mild drought, the north part of Central Region, north-west part of the Southern Region and central part of the East Coast have relatively higher severity compare to other areas in each region. Similarly, on the basis of the spatial interpolation of drought characteristics it is suggested that more streamflow stations be installed in each region for better observation as high spatial variation was observed in this study and more detailed representation are required. In conclusion, the SDI-3 is applicable for drought identification and monitoring in all three Central Region, Southern Region and East Coast, with the recommendation of increasing the number of streamflow stations. The generated and validated information (e.g. SDI-3) in this study can be further utilized as input to forecast models to predict and prepare for the events in the future.

\section{CONFLICT OF INTEREST}

The authors declare no conflict of interest.

\section{AUTHOR CONTRIBUTIONS}

Kit Fai Fung, Yuk Feng Huang, Chai Hoon Koo conducted the research; Yuk Feng Huang and Chai Hoon Koo processed the data; Kit Fai Fung analyzed the data; Kit Fai Fung, Yuk Feng Huang, Chai Hoon Koo wrote the paper; all authors had approved the final version of this work.

\section{REFERENCES}

[1] A. J. Shaaban and K. S. Low, "Droughts in Malaysia: A look at its characteristics, impacts, related policies and management strategies," in Proc. the Water and Drainage 2003 Conference, 2003.

[2] K. S. Hussain and B. Zainudin, "Effect of monsoonal fluctuations on micro-phytoplankton and chlorophyll - A relationship in reefs ecosystems of South China Sea," Journal of Sustainability Science and Management, vol. 2018, issue 5, pp. 191-201, 2018.

[3] T. B. McKee, N. J. Doesken, and J. Kleist, "The relationship of drought frequency and duration to time scales," presented at the Eighth Conference on Applied Climatology, California, Jan. 17-22, 1993.

[4] G. Tsakiris and H. Vangelis, "Establishing a drought index incorporating evapotranspiration," European Water Publications, vol. 9/10, pp. 3-11, Jan 2005.

[5] S. M. Vicente-Serrano, S. Beguería, and J. I. López-Moreno, "A multiscalar drought index sensitive to global warming: The standardized precipitation evapotranspiration index," Journal of Climate, vol. 23, issue 7, pp. 1696-1718, Apr. 2010.

[6] W. C. Palmer, Meteorological Drought, US Department of Commerce: Weather Bureau Washington, D.C., Feb. 1965.

[7] W. C. Palmer, "Keeping track of crop moisture conditions, nationwide: the new crop moisture index," Weatherwise, vol. 21, issue 4, pp. 156-161, Aug. 1968

[8] F. N. Kogan, "Droughts of the late 1980s in the United States as derived from NOAA polar-orbiting satellite data," Bulletin of the American Meteorology Society, vol. 76, issue 5, pp. 655-668, 1995. 
[9] B. Shafer and L. Dezman, "Development of a surface water supply index (SWSI) to assess the severity of drought conditions in snowpack runoff areas," in Proc. the Western Snow Conference, 1982, pp. $164-175$.

[10] I. Nalbantis and G. Tsakiris, "Assessment of hydrological drought revisited," Water Resources Management, 23, pp. 881-897, Jul. 2008.

[11] Y. F. Huang, J. T. Ang, Y. J. Tiong, M. Majid, and Mohd Zaki. "Drought forecasting using SPI and EDI under RCP-8.5 climate change scenarios for langat river basin, Malaysia," Procedia Engineering, vol. 154, issue 2016, pp. 710-717, 2016.

[12] Y. W. Soh, C. H. Koo, Y. F. Huang, and K. F. Fung, "Application of artificial intelligence models for the prediction of standardized precipitation evapotranspiration index (SPEI) at Langat River Basin, Malaysia," Computers and Electronics in Agriculture, vol. 144 pp. 164-173, 2018

[13] K. F. Fung, Y. F. Huang, C. H. Koo and M. Majid, "Improved SVR machine learning models for agricultural drought prediction at downstream of langat river basin, Malaysia," Journal of Water and Climate Change, doi: 10.2166/wcc.2019.295, Jun. 2019

[14] K. F. Fung, Y. F. Huang, C. H. Koo, and K. W. Tan, "Standardized precipitation index (SPI) and standardized precipitation evapotranspiration index (SPEI) drought characteristic and trend analysis using the second generation Canadian earth SYSTEM model (CanESM2) outputs under representative concentration pathway (RCP) 8.5," Carpathian Journal of Earth and Environmental Sciences, vol. 14 issue 2, Aug 2019

[15] K. F. Fung, Y. F. Huang, and C. H. Koo, "Improvement of SVR-based drought forecasting models using wavelet pre-processing technique," in Proc. International Conference on Civil \& Environmental Engineering, 2018.

[16] K. F. Fung, Y. F. Huang, C. H. Koo, and Y. W. Soh, "Drought forecasting: A review of modelling approaches: 2007-2017," Journal of Water and Climate Change, doi: 10.2166/wcc.2019.236, 2019.

[17] T. Huang, L. Xu, and H. F, "Drought characteristics and its response to the global climate variability in the Yangtze River Basin, China," Water, vol. 11, issue 1, pp. 13, Dec. 2018.

[18] L. Zhao, J. J. Wu, and J. Fang, "Robust response of streamflow drought to different timescales of meteorological drought in Xiangiiang River Basin of China," Advances in Meteorology, 2016, doi: 10.1155/2016/1634787.

[19] DOSM, Preliminary Count Report 2010, Department of Statistics (DOSM), Malaysia, 2010.

[20] V. M. Yevjevich, An Objective Approach to Definition and Investigations of Continental Hydrologic Droughts, vol. 23, Colorado State University, Fort Collins, Colorado, 1967.

[21] A. K. Mishra and V. R. Desai, "Drought forecasting using stochastic models," Stochastic Environmental Research and Risk Assessment, vol 19, pp. 326-339, Nov 2005.
[22] W. H. Nam, M. J. Hayes, M. D. Svoboda, T. Tadesse, and D. A. Wilhite, "Drought hazard assessment in the context of climate change for South Korea," Agricultural Water Management, vol. 160, pp. 106-117, Oct 2015.

[23] S. H. Lee, S. H. Yoo, J. Y. Choi, and S. Bae, “Assessment of the impact of climate change on drought characteristics in the Hwanghae Plain, North Korea using time series SPI and SPEI: 1981-2100," Water, vol. 9, 579, Aug 2017.

[24] M. Montaseri and B. Amirataee, "Comprehensive stochastic assessment of meteorological drought indices," International Journal of Climatology, vol. 37, pp. 998-1013, May 2016.

Copyright (C) 2020 by the authors. This is an open access article distributed under the Creative Commons Attribution License which permits unrestricted use, distribution, and reproduction in any medium, provided the original work is properly cited (CC BY 4.0).

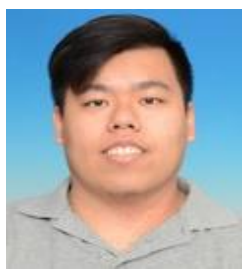

Kit Fai Fung has a master degree in civil engineering from Universiti Tunku Abdul Rahman (UTAR) Currently, he is pursuing his $\mathrm{PhD}$ in the field of water resources engineering at Universiti Tunku Abdul Rahman (UTAR), Malaysia. His thesis aims to work with drought indices and artificial intelligence model for drought monitoring and forecasting.

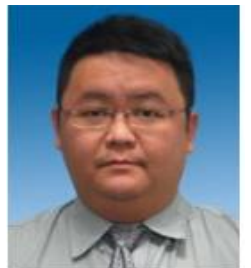

Yuk Feng Huang has his $\mathrm{PhD}$ in water resources engineering from Universiti Putra Malaysia (UPM), Malaysia. Currently, he is the associate professor at UTAR and also as the chairperson of Center of Disaster Risk Reduction (CDRR). His research interests include water resources studies, climate change studies, drought forecasting and management, potential evapotranspiration estimation and artificial intelligence modelling.

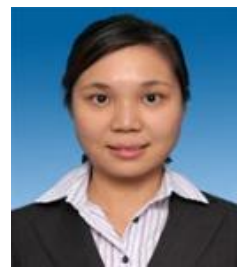

Chai Hoon Koo has her PhD in civil \& structural engineering from Universiti Kebangsaan Malaysia (UKM), Malaysia. Currently, she is the assistant professor at UTAR and also as the Secretary of Center of Disaster Risk Reduction (CDRR). Her research interests include water quality and recycling, membrane filtration, drought forecasting and management, potential evapotranspiration estimation and artificial intelligence modelling. 